Available online at GSC Online Press Directory

GSC Biological and Pharmaceutical Sciences

e-ISSN: 2581-3250, CODEN (USA): GBPSC2

Journal homepage: https://www.gsconlinepress.com/journals/gscbps

(RESEARCH ARTICLE)

\title{
Development and evaluation of sustained release microparticles of atenolol of gastrointestinal delivery
}

\author{
Aduri Prakash Reddy*, Shaik Uddandu Saheb, Moodu Maheswari, Gaddam Suvarsha and Anga Monika
}

Dhanvanthari Institute of Pharmaceutical Sciences, Kothagudem, Telangana, India, 507120.

Publication history: Received on 25 March 2018; revised on 14 May 2018; accepted on 15 May 2018

https://doi.org/10.30574/gscbps.2018.3.2.0026

\begin{abstract}
The aim of the present study is to development and evaluation of sustained release micro particulates of atenolol prepared by solvent evaporation technique. In this method Eudragit RS-100 was dissolved in Acetone and suitable solvent was mixed well with the pure Atenolol drug with different ratios and filtered it. Add magnesium stearate and it was dispersed in solution by ultra sonification. This solution keep it on a side and take another fresh beaker contain $100 \mathrm{ml}$ of liquid paraffin and add $20 \mathrm{ml}$ of $\mathrm{n}$-hexane. Both liquid paraffin and $\mathrm{n}$-hexane stirred continuously by using mechanical stirrer. In this solution add previous ultra sonification solution in the form of drops with the help of syringe until acetone evaporated. By this process microparticles were formed and they dried at room temperature. The drug product percentage yield, drug entrapment efficiency, particles size parameters are in desired manner. The in-vitro drug release studies Shows that the percentage of drug release is in standard level. Among all formulations F3 and F5 formulations with drug, polymer was found to be satisfactory in terms of excellent micromeritic properties, percent yield (92.12\%), Drug entrapment efficiency (77.79\%), Percent buoyancy (80\%) and highest in-vitro drug release of $85.60 \%$ in sustained manner over an extended period of time for $12 \mathrm{hrs}$.
\end{abstract}

Keywords: Atenolol; Microparticles; Eudragit RL 100; Magnesium stearate

\section{Introduction}

The Micro particulate Drug Delivery System (MDDS) is one of the processes to provide the Sustained Controlled Delivery (SDD) of drug is taken to long period of time. Micro particles are small particles of Solids (or) Small droplets of liquids surrounded by the walls of the natural \& synthetic polymer films of different types of thickness and degree of permeability its acting as a release rate of controlling substance and have a diameter up to range from $0.1 \mu \mathrm{m}$ to $200 \mu \mathrm{m}[1]$.

Atenolol, a competitive beta (1)-selective adrenergic antagonist, has the lowest lipid solubility of this drug class. Although it is similar to metoprolol, atenolol differs from pindolol and propranolol in that it does not have intrinsic sympathomimetic properties or membrane-stabilizing activity. Atenolol is used alone or with chlorthalidone in the management of hypertension and edema [2].

Micro particles is widely used in the pharmaceutical and other sciences to mask tastes or odors, impart stability to drug molecules, improve bioavailability, and as multi-particulate dosage forms to produce controlled or targeted drug delivery. It is therefore a rapidly expanding technology for achieving sustained-release dosage forms. the micro particles being produced by the solvent evaporation method.

\footnotetext{
${ }^{*}$ Corresponding author

E-mail address: aduri.prakash14@ gmail.com
}

Copyright (C) 2018 Author(s) retain the copyright of this article. This article is published under the terms of the Creative Commons Attribution Liscense 4.0. 
The main objective of this work was to investigate the possibility of obtaining a sustained release formulation of atenolol micro particles by using Eudragit RS100 and Magnesium stearate in various drugs, polymer ratios. The various physicochemical characteristics and the in-vitro release rates from these microspheres were thus examined.

\section{Material and methods}

\subsection{Preformulation studies}

Preformulation studies investigated the physicochemical properties of drug and other excipients.

\subsubsection{Selection of drugs and other ingredients}

Atenolol was selected as physicochemical and biological properties and also based on its suitability for sustained release drug delivery. Eudragit RL 100 was selected as matrix forming polymers. Magnesium stearate was selected as lubricant in the production of pharmaceutical and cosmetic products.

\subsubsection{Preparation of standard solution}

Stock solution-I: $100 \mathrm{mg}$ of atenolol was dissolved in small quantity of methanol and make up to $100 \mathrm{ml} 0.1 \mathrm{~N}$ HCL to give a concentration of $1 \mathrm{mg} / \mathrm{ml}$.

Stock solution-II: Solution II was prepared by taken $10 \mathrm{ml}$ from the stock solution-I and dissolved in $100 \mathrm{ml}$ of $0.1 \mathrm{~N}$ $\mathrm{HCL}$, so as to get a solution of $0.1 \mathrm{mg} / \mathrm{ml}$.

\subsubsection{Atenolol standard graph [3]}

From the stock solution-II $0.1 \mathrm{mg} / \mathrm{ml}$ was prepared and UV scan was taken between 200 to $400 \mathrm{~nm}$. The absorption maximum was found to be $275 \mathrm{~nm}$ and was used for the further analytical studies.

\subsection{Formulation studies}

\subsubsection{Development of microparticles}

Sustained drug delivery was prepared by solvent evaporation method [4]. The microparticles were prepared according to the formula shown in table-1. Eudragit RS-100 was weighed requisite ratio and then dissolved in Acetone and suitable solvent was mixed well with the pure Atenolol drug with different ratios and filtered drug solution, add magnesium stearate and it was dispersed in solution by ultrasonification. This solution keep it on a side and take another fresh beaker contain $100 \mathrm{ml}$ of liquid paraffin and add $20 \mathrm{ml}$ of n-hexane. Both liquid paraffin and n-hexane stirred continuously by using mechanical stirrer at $400 \mathrm{RPM}$ at room temperature for $1.30 \mathrm{hrs}$. In this solution add previous ultrasonification solution in the form of drops with the help of syringe until acetone evaporated. The microparticles were formed and washed 4-5 times in $40 \mathrm{ml} \mathrm{n}$-hexane. Finally dried at room temperature in desiccator for $24 \mathrm{hrs}$.

Table 1 Formulation design of atenolol microparticles

\begin{tabular}{lccccc}
\hline Ingredients(mg) & F1 & F2 & F3 & F4 & F5 \\
\hline Atenolol & 100 & 100 & 100 & 100 & 100 \\
Eudragit RS100 & 100 & & 200 & - & 200 \\
Magnesium stearate & - & 100 & - & 200 & 200 \\
n-Hexane & 15 & 15 & 15 & 15 & 15 \\
Liquid paraffin & 20 & 20 & 20 & 20 & 20 \\
Acetone & 20 & 20 & 20 & 20 & 20 \\
\hline
\end{tabular}




\section{Results}

\subsection{Spectroscopic studies [3]}

A solution of $0.1 \mathrm{mg} / \mathrm{ml}$ Atenolol was prepared and UV scan was taken between 200 to $400 \mathrm{~nm}$. The absorption maximum was found to be $275 \mathrm{~nm}$ in simulated gastric fluid $\mathrm{pH} 1.4$ and had good reproducibility and standard curve graph was shown in figure-1.

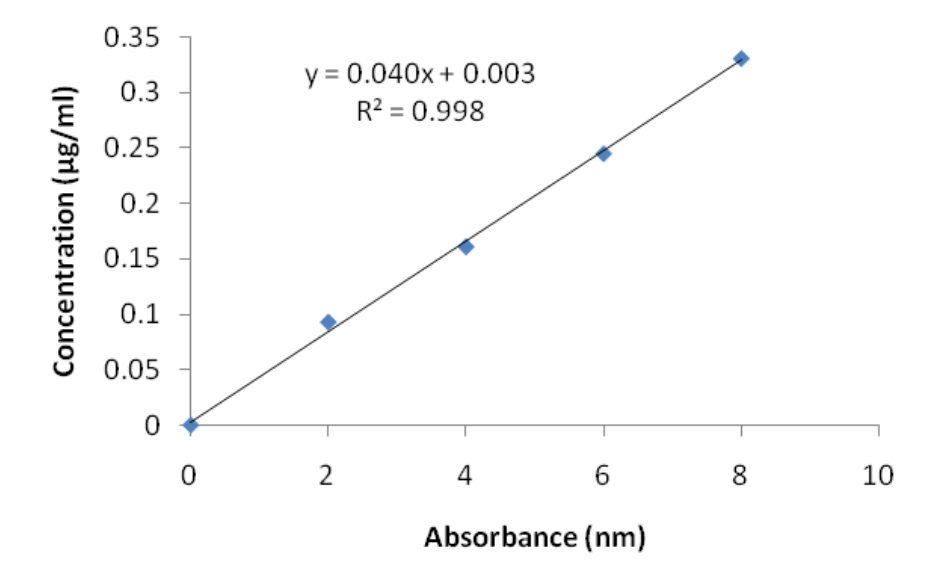

Figure 1 Standard curve of atenelol

\subsection{Percentage yield [5]}

It was observed that as the polymer ratio in the formulation increases, the microparticles product yield also increased. The low percentage yield in some formulations may be due to blocking of needle and wastage of the drug polymer solution, adhesion of polymer solution to magnetic bead and microparticles lost during the washing process. The microparticles percentage yield was recorded in table- 2 .

\subsection{Buoyancy studies [6]}

The in-vitro buoyancy was determined by floating lag time, and total floating time. The percentage buoyancy study of the prepared microparticles was recorded in table- 2 .

\subsection{Drug entrapment efficiency $[7,8]$}

Percentage of Drug entrapment efficiency of atenelol arranged from 62.58 to 69\% for microparticles containing various polymers and other Chemicals. The Drug entrapment efficiency of the prepared microparticles increased progressively with an increase in proportion of the dispersed phase. Increases the viscosity of particle size. Increased viscosity of the polymer solution at the Increases the polymer concentration would be expected to decrease the diffusion of the drug into the external phase which would result in increased entrapment efficiency. The percentage Drug entrapment efficiency of the prepared microparticles was recorded in table- 2 .

Table 2 The percentage yield, buoyancy and drug entrapment efficiency of all atenelol formulations

\begin{tabular}{lllll}
\hline Formulations & \% Yield & \% Buoyancy & $\begin{array}{l}\text { \% Drug } \\
\text { Efficiency }\end{array}$ & entrapment \\
\hline F1 & 87.2 & 64 & 62.58 \\
F2 & 89.62 & 68 & 69.72 \\
F3 & 92.12 & 72 & 77.79 \\
F4 & 90.56 & 77 & 66.58 \\
F5 & 88.52 & 74 & 69.08 \\
\hline
\end{tabular}




\subsection{Particle size [9]}

Particle sizes was determined by using microscope and calculate average of particle size. The results were shown in in figure 2

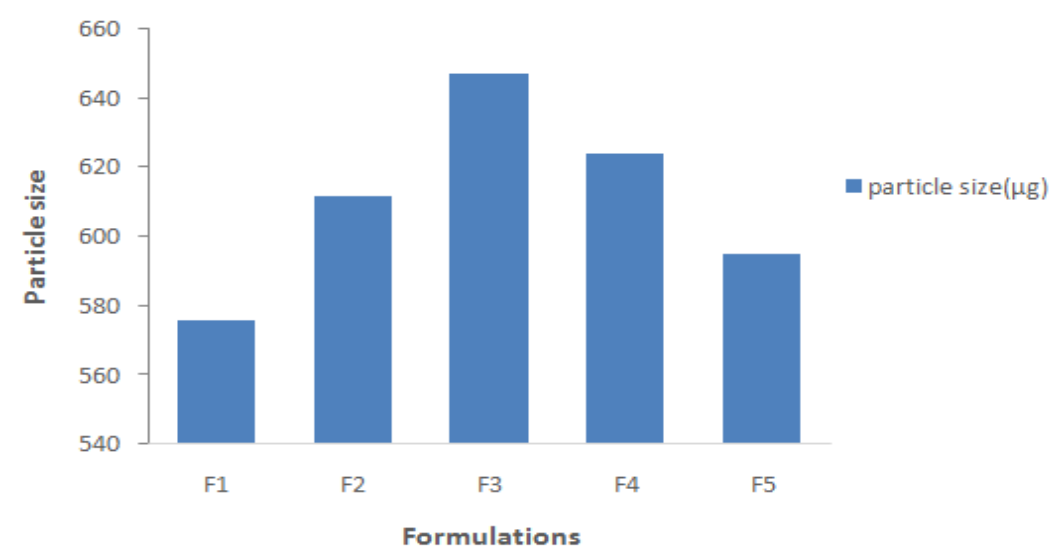

Figure 2 Graph of particle size of different atenolol formulations

\subsection{In-vitro drug release studies $[10,11]$}

In-vitro drug release studies of all formulations were carried out using dissolution apparatus USP Type-I. The dissolution studies were conducted by using dissolution media, $\mathrm{pH}$ 1.4. The results of the in-vitro dissolution studies of formulation F1 to F5 are shown in table 3.

Table 3 Percentage of cumulative drug release for all formulations

\begin{tabular}{llllll}
\hline Time (hrs) & F1 & F2 & F3 & F4 & F5 \\
\hline 0 & 0 & 0 & 0 & 0 & 0 \\
1 & 21 & 20 & 22 & 21 & 25 \\
2 & 29 & 28.1 & 31.8 & 28 & 31 \\
3 & 36 & 42.7 & 39.1 & 40.2 \\
4 & 48.2 & 49.1 & 51.8 & 48.8 & 49.5 \\
5 & 56.6 & 58.2 & 62 & 59.9 & 58.6 \\
6 & 72.1 & 69.9 & 71.8 & 70.8 & 69.8 \\
7 & 82.5 & 77.8 & 76.9 & 75.6 & 73.9 \\
8 & & 83.2 & 81.2 & 82.4 & 76.2 \\
10 & & & 85.9 & 84.3 & 80 \\
12 & & & & & 85.6 \\
\hline
\end{tabular}

\section{Conclusion}

The prepared formulations were characterized for their percentage yield, micromeritic properties, morphology, buoyancy studies, drug entrapment and drug release studies. Percentage drug entrapment efficiency ranges from 62.58 to $77.79 \%$ for microspheres containing Eudragit RL 100 and Magnesium stearate solid as the formulations showed fairly acceptable values for all the parameters evaluated. Among all formulations F3 and F5 formulations with drug; polymer was found to be satisfactory in terms of excellent micromeritic properties, percent yield (92.12\%), Drug entrapment efficiency (77.79\%), Percent buoyancy (80\%) and highest in-vitro drug release of $85.60 \%$ in sustained manner over an extended period of time for $12 \mathrm{hrs}$. 


\section{Compliance with ethical standards}

\section{Acknowledgments}

With deep gratitude, I would like to thank the Management, Dhanvanthari Institute of Pharmaceutical Sciences_for providing all the necessary equipment and facilities in the college campus to carry out inspiring research work.

\section{Disclosure of conflict of interest}

The authors declare that there is no conflict of interest.

\section{References}

[1] Lwise Donald. (2000). Hand book of pharmaceutical controlled release technology, New York, 271.

[2] Agon P, Goethals P, Van Haver D and Kaufman JM. (1991). Permeability of the blood-brain barrier for atenolol studied by positron emission tomography. Journal of Pharmacy and Pharmacology, 43 (8), 597-600.

[3] Lalitha K, Kiranjyothi R and Padma B. (2013). UV spectrophotometric method development and validation for the determination of atenolol and losartan potassium by $\mathrm{q}$ analysis. International Bulletin of Drug Research, 3(4), 54-62.

[4] Sinha VR, Singla AK, Wadhawan S, Kaushik R, Kumria R, Bansal K and Dhawan. (2004). Chitosan microspheres as a potential carrier for drugs. International Journal of Pharmaceutics, 274, 1-33.

[5] Mahmoud MA, Saleh Abd El-Rasoul, Sayed HA and Mohamed AI. (2011). Emulsification/internal gelation as a method for preparation of diclofenac sodium-sodium alginate microparticles. Saudi Pharmaceutical Journal, 21(1), 61-69.

[6] Srivastava AK, Ridhurkar DN and Wadhwa S. (2005). Floating microspheres of Cimetidine: formulation, characterization and in vivo evaluation. Acta Pharmaceutica, 55(3), 277-285.

[7] Reddy JRK, Gnanaprakash K, Badarinath AV and Chetty CMS. (2009). Formulation and evaluation of microparticles of metronidazole. Journal of Pharmaceutical Sciences and Research, 1, 131-136.

[8] Murty SB, Wei Q, Thanoo BC and Deluca PP. (2004). In vivo release characteristics of octreotide acetate from experimental polymeric microsphere formulations using oil/water and oil/oil processes. AAPS PharmSciTech $5(3), 49$.

[9] Nayak BS, Nayak UK, Patro KB and Rout PK. (2008). Preparation and in vitro evaluation of lamivudine entrapped MOI microspheres for oral administration. Research Journal of Pharmacy and Technology, 1(4), 4379.

[10] Gohel MC and Amin AF. (1999). Studies in preparation of Diclofenac sodium microspheres by solvent evaporation technique using response surface analysis. Indian Journal of Pharmaceutical Sciences, 61(1), 48-53.

[11] Umamaheswari RB, Jain S, Bhadra D and Jain NK. (2003). Floating microspheres bearing acetohydroxamic acid for the treatment of H. pylori. Journal of Pharmacy and Pharmacology, 55, 1607-13.

\section{How to cite this article}

Aduri PR, Shaik US, Moodu M, Gaddam S and Anga M. (2018). Development and evaluation of sustained release microparticles of atenolol of gastrointestinal delivery. GSC Biological and Pharmaceutical Sciences, 3(2), 01-05. 